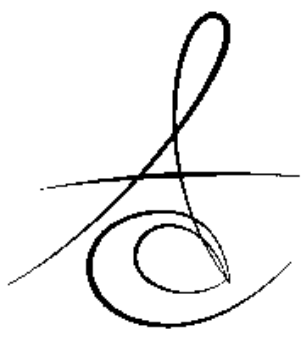

\section{ESTETİK BÖLGEDEKİ İMPLANT DESTEKLİ SABİT RESTORASYONLARDA DİŞETI ÇIKIŞ PROFİLİNİN OLUŞTURULMASI: OLGU SUNUMU}

\section{CREATING EMERGENCE PROFILE OF IMPLANT RETAINED FIXED RESTORATIONS AT THE ESTHETIC REGION: CASE REPORT}

\author{
Dok.Ögr. Ayfer ATAMER* \\ Dok. Ögr. Fatih AYÇIÇEK*
}

\author{
Dok. Ögr. Esra BİLGİ ÖZYETİM* \\ Prof. Dr. Gülsen BAYRAKTAR
}

Makale Kodu/Article code: 3031

Makale Gönderilme tarihi: 24.11.2016

Kabul Tarihi: 20.09.2016

\section{ÖZET}

Ön bölgede uygulanan restorasyonların kabul edilebilirliği için pekçok faktör bulunmaktadır. İmplantın dişler, dudaklar, dişeti ve çevre dokular ile ilişkisinin yanısıra implant pozisyonu, gülme hattı, dişeti çıkış profili, periodonsiyumun formu ve biyotipi bu faktörlerdendir. Ayrıca üst çene ön bölge diş eksikliklerinin implant destekli protezlerle tedavisi diğer bölgelere göre daha zordur. Hastaların yüksek estetik beklentileri, çıkış profili oluşturma ve doğru aktarma gerekliliği durumu daha da zorlaştırmaktadır. Bu olgu sunumunda üst ön kesici diş eksikliklerinde oklüzal vidalı geçici protezler kullanılarak çıkış profilinin oluşturulması, aktarılması ve implant destekli köprü protezi ile rehabilitasyonu anlatılmaktadır.

Anahtar Kelimeler: Dişeti çıkış profili, implant, ön bölge

\section{ABSTRACT}

There are many factors to acceptable restorastion in anterior region. The relationship between teeth, lips, gums and surronding tissues of implants as well as implant position, smile line, gingival emergence profile, biotype are one of these factors. The treatment for missing teeth with implant retained prosthesis in the maxillary anterior region is more difficult other regions. The complexity of the anterior teeth restorations are complicated because of patient's high expectations, creating emergence profile and accurately transfer.

In this case report, absance of maxillary anterior incisors restorated with implant retained fixed prostheses; created and transfered emergence profile with interim prostheses by using occlusal screw was presented.

Key Words: Emergence profile, implant, anterior region

\section{GİRİŞ}

Dental Üst çene ön bölge diş eksikliklerinin protetik tedavisi diş hekimleri için ayrıca özen gösterilmesi gereken olguların başında gelmektedir. Bu bölgede implant veya diş destekli sabit protezlerden hangisi tercih edilirse edilsin yumuşak dokuların doğal görünümü sağlanmalıdır. ${ }^{1}$ Ön bölge implant restorasyonlarının estetik başarısında; implantın dişler, dudaklar, dişeti ve çevre dokular ile ilişkisi çok önemlidir. ${ }^{2}$

$\mathrm{Bu}$ nedenle implant çevresi dokularda oluşturulmak istenen estetik görünümün öngörülebilmesi için bazı faktörlerin değerlendirilmesi ve tedavinin bu doğrultuda gerçekleştirilmesi gerekmektedir.
Bu faktörler; gülme hattı, implant pozisyonu, periodonsiyumun formu ve biyotipi, ağızda var olan diş şekli, alveol kret pozisyonu ve çıkış profili olarak sıralanmaktadır. ${ }^{2-4}$

Üst çene ön bölge implant destekli restorasyonlarda uygun yumuşak doku cevabı ve çıkış profili oluşturabilmek başlıca hedeflerdendir. Uygun çıkış profilinin oluşturulması için geçici restorasyonların kulanımı ve oluşturulan çıkış profilinin daimi restorasyona doğru aktarılması gerekmektedir. ${ }^{5}$ nedeniyle çekilen üst ön kesicilerin implant destekli köprü protezi ile rehabilitasyonu anlatılmaktadır.
$\mathrm{Bu}$ olgu sunumunda periodontal problemler

* Istanbul Üniversitesi, Diş Hekimliği Fakültesi, Protetik Diş Tedavisi AD, İstanbul. 


\section{OLGU SUNUMU}

40 yaşındaki bayan hasta, üst çene ön bölge dişlerinde mevcut olan periodontal problemleri nedeniyle İstanbul Üniversitesi Diş Hekimliği Fakültesi Periodontoloji Anabilim Dalı́na başvurmuştur. Hastadan alınan anamnezde herhangi bir sistemik rahatsızlığı olmadığı belirlenmiş ve klinik, radyolojik muayeneleri sonucunda Periodontoloji Anabilim Dalı́nda detertraj ve küretaj işlemleri yapılmış ve hastaya ağız hijyeni eğitimi verilmiştir. Protetik Diş Tedavisi Anabilim Dalı'nda yapılan muayene sonucunda hastanın 11,12,21,22 numaralı dişlerinin çekimine, 12 ve 22 numaralı dişler bölgesine 2 implant yerleştirilmesine ve implant yerleştirilmesi planlanan bölgelerdeki vertikal ve horizontal kemik kaybı nedeniyle ogmentasyon işlemi yapılmasına karar verilmiştir. Bu nedenle önce ogmentasyon yapılacak bölgedeki 12 ve 22 numaralı dişler, 4 ay sonra 11 ve 21 numaralı dişler çekilmiştir. Hastanın fonksiyon, fonasyon ve estetiğinin devamını sağlayabilmek amacıyla çekimi yapılan 12 ve 22 numaralı dişleri, kuron kök birleşim yerinin hemen altından kesilerek kuron kısımlarından santral ve kanin dişlerine kompozit ile bağlanmıştır (Resim 1).

Ogmentasyon işleminden 4 ay sonra çekilen 12 ve 22 numaralı dişler yerine implantlar yerleştirilmiş ve aynı seansta 11 ve 21 numaralı dişlerin de çekimi yapılmıştır. Geçici köprü restorasyonunun hazırlanabilmesi için polivinilsiloksan (PVS) ölçü maddesi kullanılarak hastadan kapalı ölçü yöntemi ile ölçü alınmıştır (Resim 2).
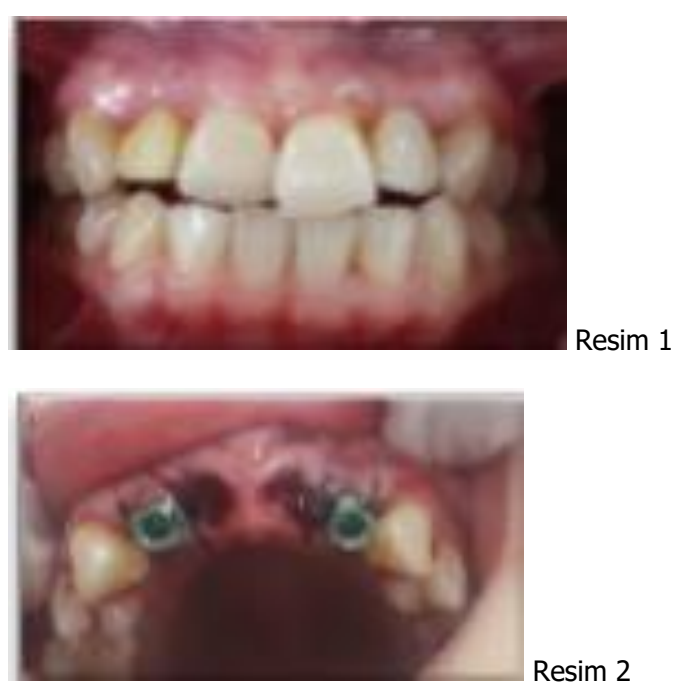

Oklüzal vidalı geçici köprü restorasyonu, plastik geçici abutmentlar kullanılarak hazırlanmış ve çekimi yapılan 11 ve 21 numaralı dişlerin çekim boş- luklarının içine de uzanacak şekilde hazırlanarak doku iyileşmesi sürecinde uygun çıkış profilinin oluşturulması amaçlanmıştır. Geçici köprü restorasyonunun oklüzyonu; sentrik ve eksentrik hareketler sırasında antagonist dişlerle temas etmeyecek şekilde düzenlenmiş ve yumuşak doku desteğini ve estetiği sağlayabilmek için implant yerleştirilmesini takiben 24 saat içinde ağıza uygulanarak, hastaya ağız hijyeni ile ilgili bilgi verilmiştir (Resim 3-5).

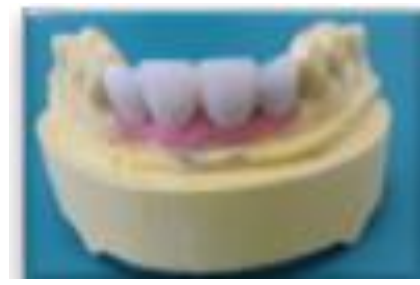

Resim 3.
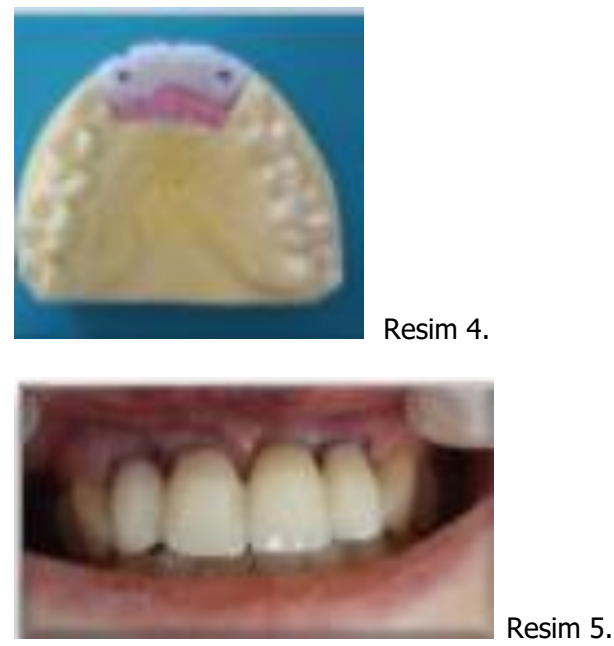

Bu olguda, oklüzal vidalı geçici köprü restorasyonu implantların osseointegrasyonu tamamlanıncaya kadar hasta ağzında bırakılmış ve osseointegrasyon süresi boyunca hiç çıkartılmamıştır. Geçici köprü restorasyonunun çıkartıldığı ilk seansta ise 21 numaralı diş bölgesinde köprü gövdesinin, dişetinde uygun şekillendirme oluşturmadığı görülmüştür (Resim 6,7). Bu nedenle dişeti çıkış profili ile birlikte papil oluşumunu sağlayabilmek amacıyla mukozada şekillendirilme yapılmasına karar verilerek servikal bölge ve gövde altı gibi alanlara akışkan kompozit ilaveleri yapılmıştır. Bu

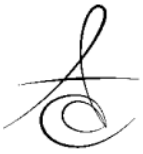


şekilde dişetinin istenilen bölgelere doğru yönlendirilebilmesi amaçlanmışıı.
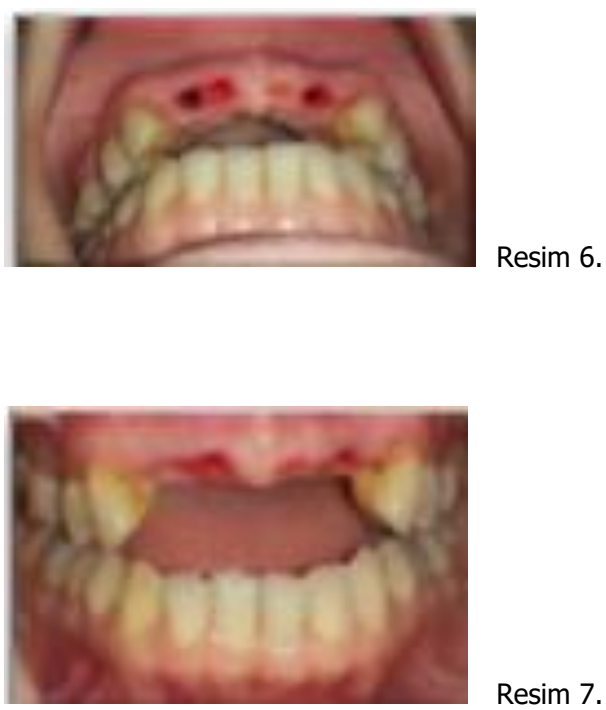

Resim 7.

Çıkış profilini oluşturabilmek için geçici restorasyonun servikal bölümüne, dokuya fazla baskı yapması sonucu oluşabilecek olumsuz etkilerin önlenmesi amacıyla yaklaşık 1 hafta aralıklarla ince tabakalar halinde akışkan kompozit ilave edilmiştir (Resim 8). Kontroller sırasında dokularda aşırı baskı oluşturabilecek bölgelerde aşındırma, eksik bölgelerde ise akışkan kompozit ilavesi yapılarak yumuşak doku şekillendirilmesi sağlanmıştır.

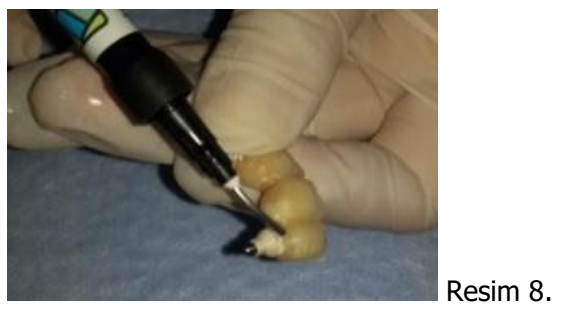

6 haftalık şekillendirme işleminin ardından uygun çıkış profili ve papil oluşumu sağlanmıştır (Resim 9,10). Daimi restorasyondan sonra oluşabilecek herhangi bir doku çekilmesini önlemek amacıyla geçici restorasyonlar 2 hafta daha hasta ağzında bırakılmıştır.

Dişeti şekillendirilmesi yapılan hastalarda mevcut durumu kaydetmek ve oluşturulan çıkış profilini daimi restorasyonlara aktarabilmek için en önemli aşamalardan biri de ölçü alma aşamasıdır. Bu nedenle, oluşturulan final doku şeklinin transferi için kişisel ölçü postu hazırlanmıştır.
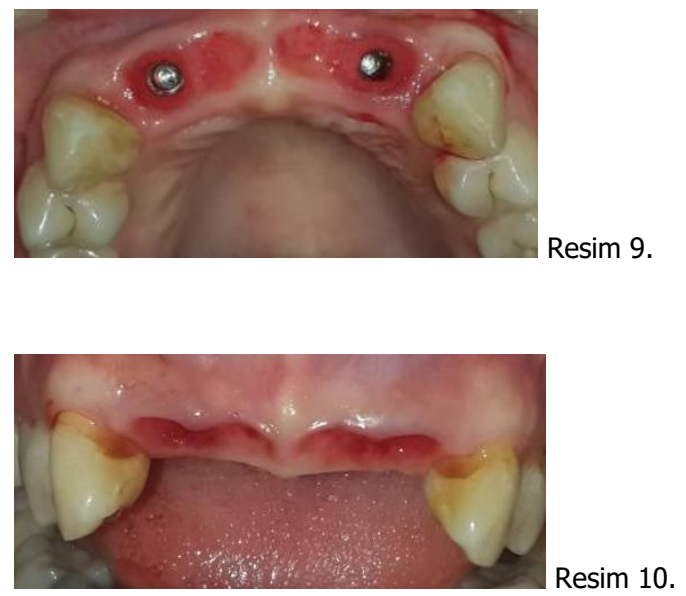

Kişisel ölçü postunun hazırlanma aşamaları aşağıdaki sıralama ile uygulanmıştır:

Analoğa vidalanan geçici restorasyon, vida deliği dışarıda kalacak şekilde ağır kıvamlı silikon ölçü maddesi içine gömülmüştür (Resim 11).

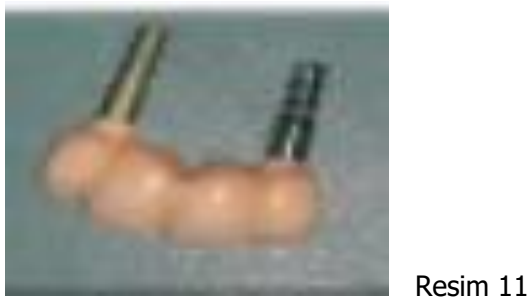

Silikonun polimerizasyonunun ardından geçici restorasyon analogtan sökülerek yumuşak dokuda oluşturulan çıkış profilinin şekli silikona aktarılmıştır.

Ardından silikonun içinde bulunan analoglara ölçü postları bağlanmıştır. Ölçü postu ve silikon arasında kalan boşluklar akışkan kompozit ile doldurularak polimerize olması sağlanmıştır (Resim 12,13).

Polimerizasyonun ardından sökülen ölçü postları ağız içine yerleştirilmiş (Resim 14) ve açık kaşık yöntemi ile PVS ölçü maddesi kullanılarak ölçü alınmıştır (Resim 15).

Alınan ölçülerden Tip 3 sert alçı ile üst çene modeli elde edilmiştir. Bu olguda, dişeti biyotipinin ince ve estetik beklentinin de yüksek olmasından dolayı zirkonya abutment kullanımı ve tam seramik restorasyon yapımı tercih edilmiştir.

Kişisel olarak hazırlanan zirkonya abutmentların ağızda provası yapılmıştır (Resim 16,17). Bir sonraki seansta tam seramik restorasyonun estetiği, uyumu ve oklüzal ilişkileri kontrol edildikten sonra restorasyon

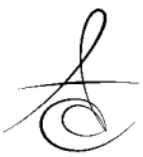


resin siman ile zirkonya abutmentların üzerine simante edilmiştir (Resim 18).

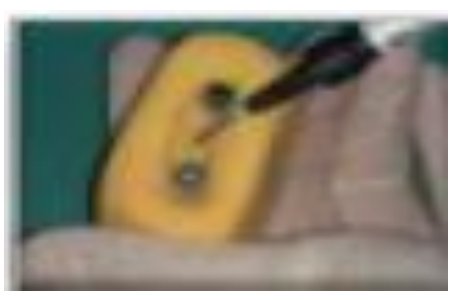

Resim 12.

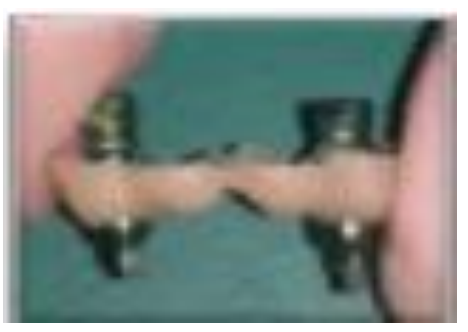

Resim 13.

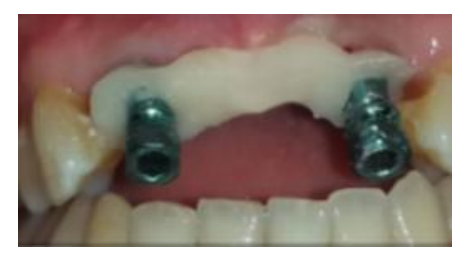

Resim 14.
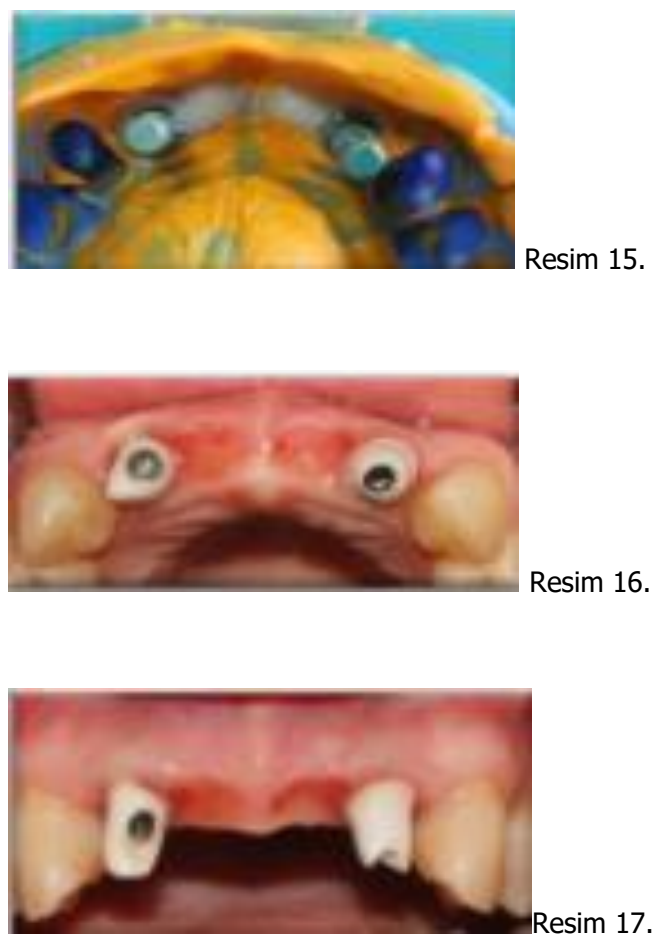

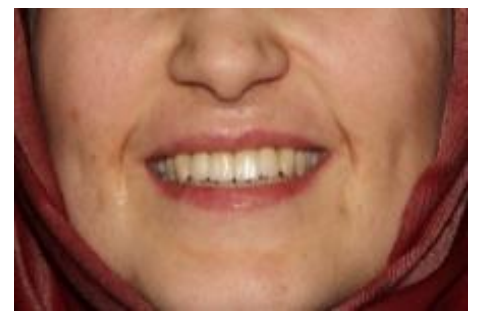

Resim 18

\section{TARTIŞMA}

Ön bölge implant restorasyonlarında başarılı bir estetik sağlayabilmek için çıkış profili doğal dişlerin profilini taklit etmelidir. ${ }^{6}$ Periimplant mukoza şekillendirilerek doğru çıkış profilinin oluşturulabilmesi için en uygun yöntem geçici protezlerin kullandırılmasıdır. Çıkış profilinin oluşturulması sırasında geçici proteze yapılan kompozit ilavelerinin mukoza üzerindeki ilk tepkisinin iskemik tipte olduğu bildirilmektedir. Bu nedenle kompozit ilavelerinin tek seferde ve aşırı miktarda yapılmaması önerilmekte ve dokuda gözlenen iskeminin yaklaşık 10- 15 dakika içinde kaybolması gerektiği bildirilmektedir. Bu durumun kontrolü ve sınırlandırılabilmesi için oluşan iskemik alanın komşu dişlerin mesiodistal genişliğinin yarısını geçmemesi gerektiği de belirtilerek, doku hasarı ve sonucunda da nekroz oluşmasını önlemek için randevu sırasında perfüzyon yeniden sağlanana kadar beklenmesi önerilmektedir. ${ }^{7}$

Günümüzde birçok yazar ${ }^{6,8,9}$, özellikle geçici restorasyonların daha sık takılıp çıkartılması gerektiği durumlarda, simanın dişeti dokusunda neden olabileceği irritasyonların önlenebilmesi amacıyla oklüzal vidalı geçici restorasyonların simante restorasyonlara tercih edilmesi gerektiğini belirtmektedirler.

Levin ve ark. ${ }^{10}$, geçici restorasyonların sert ve yumuşak doku iyileşmesini korumak ve osseointegrasyonu riske atmamak için minimum 8 hafta çıkarımadan ağızda kalması gerektiğini ifade etmektedir.

Tarnow ve ark. $^{4}$, Elian ve ark. $^{6}$ daimi protezlerden önce pek çok olguda yumuşak doku değişikliklerinin yapılması gerektiğini belirtmektedirler. Başarılı bir estetik sonuç elde etmenin önemli aşamalarından birinin de, ayrıntılı bir ölçü transferi yapabilmek olduğu bildirilmektedir. ${ }^{11}$ Standart iyileşme başlıkları ve ölçü parçaları yuvarlak şekilli olduklarından doğal dişleri tam olarak taklit edemedikleri için kişiselleştirilen ölçü parçaları ile implant çevresindeki mukozanın desteklenebileceği bildirilmektedir. Bu şekilde doku kollapsı, volümetrik değişiklikler gibi so- 
runlar ile karşılaşılmayacağı ve şekillendirilen yumuşak dokunun stabilitesini devam ettirebileceği belirtilmektedir. ${ }^{12}$

Estetik protez planlamasında seçilecek abutment da oldukça önemlidir. ${ }^{13}$ Günümüzde en çok kullanılan abutmentların titanyum, zirkonya ve hibrit abutment sistemleri olduğu bildirilmektedir (Resim 27).

Titanyum mükemmel stabilitesi, distorsiyona direnci $^{14}$ ve uzun dönem klinik çalışmalardaki başarısı $^{15,16}$ ile implant destekli protezlerin klinik ömürleri açısından abutment materyalleri içinde altın standart olarak kabul edilmekteydi. ${ }^{17}$ Günümüzde estetiğin daha ön plana çıkması ile birlikte titanyum abutmentlerın, sahip oldukları koyu gri rengin implant çevresinde ki mukozada oluşturduğu gri yansıma nedeniyle tüm vakalar için yeterli olamayacağı bildirilmektedir. ${ }^{18-21}$ Ancak düşük gülme hattı, kalın dişeti biyotipi ve estetik beklentinin fazla olmadığı olgularda ise titanyum abutmentlar kullanılabileceği belirtilmektedir. Yüksek gülme hattı, ince biyotip ${ }^{22}$ ve özellikle estetik beklentinin fazla olduğu hastalarda ise zirkonya abutmentların tercih edilmesi gerektiği önerilmektedir. ${ }^{22-26}$ Bu olguda, dişeti biyotipinin ince ve estetik beklentinin yüksek olması nedeniyle zirkonya abutment kullanımı tercih edilmiştir.

Bu olguda, ön bölge diş eksikliğinde başarılı bir estetik sağlayabilmek için daimi restorasyon yapımı öncesinde oklüzal vidalı geçici restorasyon kullanılarak dişeti çıkış profili ve papil oluşumu sağlanmıştır. Ayrıca hazırlanan yumuşak doku şeklinin tam olarak aktarılabilmesi için ölçü parçaları da kişiselleştirilmiştir. Böylece şekillendirilen yumuşak dokunun stabilitesi de sağlanarak bu alan alçı modele tam olarak aktarılabilmiştir. Elde edilen model üzerinde hazırlanan restorasyonun 6 ay süresince rahat bir şekilde kullanılabildiği hasta tarafından ifade edilmektedir.

Ön bölge diş eksikliklerinde estetik beklentilerin fazlalığı protetik restorasyon yapımını zorlaştırmaktadır. Bu olgu bildiriminde olduğu gibi üst ön bölgede diş eksikliği olanlarda dişeti çıkış profilinin oluşturulabilmesi ve doğru aktarılabilmesinde açıklanan yöntemin başarı ile kullanılabileceği düşünülmektedir.

Ayfer Atamer: ORCID ID: 0000-0002-8092-6617

Esra Bilgi Özyetim: ORCID ID: 0000-0002-3357-3740

Fatih Ayçiçek: ORCID ID: 0000-0002-8189-0740

Gülsen Bayraktar: ORCID ID: 0000-0002-7141-0598

\section{KAYNAKLAR}

1. Chiche GJ, Pinault A. Esthetics of Anterior Fixed Prosthodontics, 1st ed. Chicago; Quintessence publishing Co.Inc: 1994.p.13.

2. Ritu Batra, Sanjay Kalra, Hemant Batra. Implant esthetics. Indian Journal of Dentistry. 2010;3:1520

3. Kois JC. Predictable single tooth peri-implant esthetics: five diagnostic keys. Compend Contin Educ Dent 2004;25:895-6

4. Tarnow D, Elian N, Fletcher $P$, Froum $S$, Magner $A$, Cho SC, Salama M, Salama H, Garber DA. Vertical distance from the crest of bone to the height of the interproximal papilla between adjacent implants. J Periodontol. 2003;74:1785-8.

5. Papadopoulos I, Pozidi G, Goussias H, Kourtis S. Transferring the emergence profile from the provisional to the final restoration. ] Esthet Restor Dent 2014;26:154-61

6. Elian N, Tabourian G, Jalbout ZN et al. Accurate transfer of peri-implant soft tissue emergence profile from the provisional crown to the final prosthesis using an emergence profile cast. J Esthet Restor Dent 2007;19:306-14

7. Wittneben JG, Buser D, Belser UC, Brägger U. Periimplant soft tissue conditioning with provisional restorations in the esthetic zone: the dynamic compression technique. Int J Periodontics Restorative Dent 2013;33:447-55.

8. Parpaiola A, Sbricoli L, Guazzo R, Bressan E, Lops D. Managing the peri-implant mucosa: a clinically reliable method for optimizing soft tissue contours and emergence profile. J Esthet Restor Dent 2013; 25:317-23.

9. Shor A, Schuler R, Goto Y. Indirect implantsupported fixed provisional restoration in the esthetic zone: fabrication technique and treatment workflow. J Esthet Restor Dent 2008;20:82-95

10. Levin BP, Wilk BL. Immediate provisionalization of immediate implants in the esthetic zone: a prospective case series evaluating implant survival, esthetics, and bone maintenance. Compend Contin Educ Dent 2013;34:352-61.

11. Azer SS. A simplified technique for creating a customized gingival emergence profile for implantsupported crowns. J Prosthodont 2010;19:497-501 
12. Nelson SJ: Wheeler's dental anatomy, physiology and occlusion.9th ed. St. Louis; Saunders Elsevier: 2009

13. Ekren O, Kurtoğlu C. Dayanak implant birleşme tipinin implant destekli sabit restorasyonların klinik başarısına etkisi konusunda bir derleme. Atatürk Üniv Diş Hek Fak Derg 2009;19:131-7.

14. Andersson $B$, Odman $P$, Lindvall AM, Lithner B.Single-tooth restorations supported by osseointegrated implants: results and experiences from a prospective study after 2 to 3 years. Int J Oral Maxillofac Implants 1995;10:702-711.

15. Lekholm U, Gunne J, Henry P, Higuchi $K$, Lindén $U$, Bergström C, van Steenberghe D. Survival of the Brånemark implant in partially edentulous jaws: a 10-year prospective multicenter study. Int J Oral Maxillofac Implants 1999;14:639-45.

16. Ekelund JA, Lindquist LW, Carlsson GE, Jemt $T$. Implant treatment in the edentulous mandible: a prospective study on Brånemark system implants over more than 20 years. Int J Prosthodont 2003; 16:602-8.

17. Zembic A, Sailer I, Jung RE, Hämmerle $\mathrm{CH}$. Randomized-controlled clinical trial of customized zirconia and titanium implant abutments for singletooth implants in canine and posterior regions: 3year results. Clin Oral Implants Res 2009;20:8028.

18. Bulem Yüzügüllü, Mehmet Avcl. Esthetic Implant Abutments In Maxillary Anterior Region. ADO Journal Of Clinical Sciences 2008;2:116-22.

19. Abrahamsson I, Berglundh T, Glantz PO, Lindhe J. The mucosal attachment at different abutments. An experimental study in dogs. J Clin Periodontol 1998;25:721-7.

20. Jung RE, Sailer I, Hämmerle $\mathrm{CH}$, Attin T, Schmidlin $P$. In vitro color changes of soft tissues caused by restorative materials. Int J Periodontics Restorative Dent 2007;27:251-7.

21. Park SE, Da Silva JD, Weber HP, Ishikawa-Nagai S. Optical phenomenon of peri-implant soft tissue. Part I. Spectrophotometric assessment of natural tooth gingiva and peri-implant mucosa. Clin Oral Implants Res 2007;18:569-574.

22. Henriksson $\mathrm{K}$, Jemt T. Evaluation of custom-made Procera ceramic abutments for single implant tooth replacement: A prospective 1-year follow-up study. Int J Prosthodont 2003;16:626-630.
23. Andersson $B$, Taylor A, Lang $B R$, Scheller $H$, Schärer $P$, Sorensen JA, Tarnow D. Alumina ceramic implant abutments used for single-tooth replacement: a prospective 1- to 3-year multicenter study. Int J Prosthodont 2001;14:4328.

24. Andersson B, Glauser R, Maglione M, Taylor A. Ceramic implant abutments for short-span FPDs: a prospective 5-year multicenter study. Int J Prosthodont 2003;16:640-6.

25. Boudrias $P$, Shoghikian E, Morin E, Hutnik P. Esthetic option for the implant-supported single tooth restoration - treatment sequence with a ceramic abutmant. J Can Dent Assoc 2001;67: 508-14.

26. Tan PL, Dunne JT Jr. An esthetic comparison of a metal ceramic crown and cast metal abutmant with an all-ceramic crown and zirconia abutmant: a clinical report. J Prosthet Dent 2004;91:215-8.

\author{
Yazışma Adresi \\ Dok.Ögr. Ayfer ATAMER \\ İstanbul Üniversitesi \\ Diş Hekimliğ Fakültesi \\ Protetik Diş Tedavisi Anabilim Dalı 2. kat \\ e-mail: ayferatamer@hotmail.com
}

